\title{
THE FULL COST OF INTERCITY HIGHWAY TRANSPORTATION
}

\author{
DAVID M. LEVINSON* and DAVID GILLEN \\ Institute of Transportation Studies, University of California at Berkeley, McLaughlin Hall, Rm. 109, Berkeley, \\ CA 94720, U.S.A.
}

(Received 25 August 1997; in revised form 30 November 1997)

\begin{abstract}
In this paper we review the theoretical and empirical literature on the cost structure of the provision of intercity highway transportation and specify and estimate our own cost functions. We develop a full cost model which identifies the key cost components and then estimate costs component by component: user costs, infrastructure costs, time and congestion costs, noise costs, accident costs, and pollution costs. The total long run average cost is $\$ 0.34$ per vehicle $\mathrm{km}$ traveled. The single largest cost category is freeflow travel time. While the marginal cost of infrastructure is higher than its average cost, indicating that new construction is increasingly expensive, the marginal cost of driving (user fixed and variable costs) is less than the average cost, indicating that by increasing travel the user can spread his fixed cost of a vehicle over more trips without penalty. (C) 1998 Elsevier Science Ltd. All rights reserved
\end{abstract}

Keywords: Full cost, externalities, social cost, highway expenditures, transportation economics

\section{INTRODUCTION}

There has been a great deal of recent interest in identifying and measuring the full costs of transportation, particularly highways (see for instance: Keeler et al., 1975; Fuller et al., 1983; Quinet, 1990; Mackenzie et al., 1992; INRETS, 1993; Miller and Moffet, 1993; IBI Group, 1995; IWW/ INFRAS, 1995; Delucchi, 1996; Levinson et al., 1996). This debate questions whether various modes of transportation are implicitly subsidized and to what extent this biases investment and usage decisions. While environmental impacts are used to stop new infrastructure, the full costs to society of transportation are not generally calculated for financing projects or charging for their use.

In this paper we review the theoretical and empirical literature on the cost structure of the provision of intercity highway transportation and specify and estimate our own cost functions. In defining this framework we distinguish between internal (private) and external (social) costs, long and short run costs, and average and marginal costs. We also explore the various scale and scope economies that arise in the provision of transportation services.

In general, highway segments produce two outputs: traffic flow which requires capacity in terms of the number of lanes, and standard axle loadings which require durability in terms of the thickness of the pavement. As early as 1962, Mohring and Harwitz demonstrated that the financial viability of an infrastructure facility, under optimal pricing and investment, will depend largely upon the characteristics of its cost function. To quote Winston (1991): "If capacity and durability costs are jointly characterized by constant returns to scale, then the facility's revenue from marginal cost pricing will fully cover its capital and operating costs. If costs are characterized by increasing returns to scale, then marginal cost pricing will not cover costs; conversely, if costs are characterized by decreasing returns to scale, marginal cost pricing will provide excess revenue."

The cost characteristics for infrastructure providers include scale, scope and economies. Scale economies refer to the size of a facility; for example, is it cheaper per lane to build three lanes than it is to provide two? If so, there are economies of scale in the provision of highways. 
Small et al. (1989) refer to scope economies in highways when both capacity (number of lanes) and durability (the ability to carry heavier vehicles) are supplied.

This paper will proceed by first discussing some relevant aspects of economic theory, including external and internal costs and economies of scale and scope. Next is a development of the full cost model which identifies the key cost components. This is followed by estimation of costs component by component: user costs, infrastructure costs, time and congestion costs, noise costs, accident costs, and pollution costs. The paper concludes by summarizing the full costs of highway infrastructure and drawing some general points about the magnitude of each component. For space reasons, the comparison of the social cost results from this work with other studies are not contained in this paper, the interested reader is referred to a companion paper: The Social Costs of Intercity Passenger Transportation: A Review and Comparison of Air and Highway, (Levinson et al., 1998), which treats the subject in more detail.

\section{ECONOMIC THEORY}

\subsection{External and internal costs}

Economics has a long tradition of distinguishing those costs which are fully internalized by economic agents (internal or private costs) and those which are not (external or social costs). Agents (individuals, households, firms, and governments) in interrelated markets interact by buying and selling goods and services, as inputs to and outputs from production. The costs and benefits voluntarily interacting agents convey or impose on one another are fully reflected in the prices which are charged. However, when the actions of one economic agent alter the environment of another economic agent, there is an externality ${ }^{1}$. More formally, "an externality refers to a commodity bundle that is supplied by an economic agent to another economic agent in the absence of any related economic transaction between the agents" (Spulber, 1989). The essential distinction which is made is harm committed between strangers which is an external cost and harm committed between parties in an economic transaction which is an internal cost.

When estimating external costs, we are using the estimated amount of economic damages produced by the externality, rather than the cost of preventing that damage in the first place. Rational economic actors would choose the lower of prevention costs or damage costs when costs are internalized. This should bias the results upward (if there were a cheaper prevention measure, it could be used, but if prevention were more expensive, then the actors would accept damages, the cost value we use here).

\subsection{Economies of scale and scope}

The long run average cost curve, formed by the envelope of the short run average cost curves, often decreases over a broad range of output as size of the producer expands in both output and capacity, giving rise to economies of $\operatorname{scale}^{2}$. The presence of economies at the relevant range of producer size means that the larger the size of the producer, the lower the average or per-unit cost of output. If there were significant scale economies, it would imply that fewer and larger producers (highway authorities) would be more efficient.

Typically, a highway is used to produce a large number of conceptually distinct products, differentiated by time, space, and quality generating joint and common costs. The presence of joint and common costs gives rise to economies of scope, the cost characteristic that a single firm multiproduct technology is less costly than a single product multi-firm technology. Whether scope economies exist and the extent to which they exist depend upon both the number of products and the level of each output.

\footnotetext{
${ }^{1}$ An action by which one consumer's purchase changes the prices paid by another is dubbed a 'pecuniary externality' and is not analyzed here further; rather it is the non-pecuniary externalities with which we are concerned.

${ }^{2}$ Another note of terminology should be mentioned. Economies of scale is a cost concept, returns to scale is a related idea but refers to production, and the quantity of inputs needed. If we double all inputs, and more than double outputs, we have increasing returns to scale. If we have less than twice the amount of outputs, we have decreasing returns to scale. If we get exactly twice the output, then there are constant returns to scale. In this study, since we are referring to costs, we use economies of scale. The presence of economies of scale does not imply the presence of returns to scale.
} 


\section{FULL COST MODEL}

The method we use to estimate the full cost $(F C)$ of highway travel combines elements from a number of sources, including User Costs $\left(C_{U}\right)$, Infrastructure Costs $\left(C_{I}\right)$, Environmental Costs $\left(C_{E}\right)$, Noise Costs $\left(C_{N}\right)$, Accident and Safety Costs $\left(C_{A}\right)$, and Time Costs $\left(C_{T}\right)$. Each of these costs is a function of various parameters, which may include usage of the system. Thus, in many ways, full cost depends upon demand, so we examine both the function and the range of point estimates based upon assumptions of demand and other factors.

First, we measure total costs borne by users of the system $\left(C_{U T}\right)$. These include the cost of vehicle ownership (as measured by depreciation) and the cost of operating and maintaining the vehicle (including gas, tires, repairs and such). Costs borne by users also include the costs of taxes and insurance. Although the cost of taxes and insurance are borne by users, they are transfers to other cost categories (infrastructure, accident and safety). The transferred costs are subtracted from user costs, they are labeled user transfers $\left(T_{U}\right)$.

The next category is infrastructure costs. Here we look at state level expenditures, including federal transfer payments as well as the expenditures of lower levels of government. Highway travel, like other modes, is wrought with common and joint costs between different trip classes and vehicle types. Using econometric analysis, we estimate the short and long run average as well as the marginal cost (government expenditure) per vehicle kilometer traveled accounting for different vehicle types.

Finally we add social costs which include damage to the environment $\left(C_{E}\right)$, which is the monetized consideration for pollution and property damage in addition to the estimated costs of global climate change; the decline in property value due to noise $\left(C_{N}\right)$; and the full cost of accidents $\left(C_{A}\right)$, regardless of incidence. While noise and environmental damage costs are pure externalities, in that their incidence falls on those outside the system, accident and congestion costs are inflicted by one system user on another. Time costs $\left(C_{T}\right)$ are divided into two components, one reflecting freeflow travel time, the other reflecting the increase in time due to congestion (other users). The full cost is then computed with the following formula:

$$
F C=\left(C_{U T}-T_{U}\right)+C_{I}+C_{E}+C_{N}+C_{A}+C_{T}
$$

\section{USER COSTS AND TRANSFERS}

\subsection{A model of car price}

The cost of operating a vehicle depends upon numerous factors, many of which are decided by the user. An important such factor is the size of the vehicle. In 1995, the most popular cars were intermediates, and that is the type assumed in this analysis of cost. The operating costs considered in the analysis include gas, oil, maintenance and tires. Insurance costs (fire/theft, collision, and property damage/liability) and license, registration, taxes, and depreciation are typically considered transfers (at least in part) and must not be double counted, and so are not considered here, but rather in later sections. For instance, the full cost of accidents can neither be considered a solely social cost nor solely a private cost. Insurance simply transfers part of the financial incidence of accidents from drivers to an insurance pool. Similarly, license, registration, and taxes pay for part of constructing, maintaining, and operating the highway system. We can express this intricate cost accounting system as a series of equations:

$$
\begin{gathered}
C_{U T}(Y)=f\left(C_{g}, C_{o}, C_{t}, C_{f}, C_{p}, C_{c}, C_{l}, C_{d}(A, Y), A, Y\right) \\
=\left(C_{g}+C_{o}+C_{t}\right) Y+C_{f}+C_{p}+C_{c}+C_{l}+C_{d}(A, Y) \\
T_{U}(Y)=C_{f}+C_{p}+C_{c}+C_{l} \\
C_{U N}(Y)=C_{U T}-T_{U}=\left(C_{g}+C_{o}+C_{t}\right) Y+C_{d}(A, Y)
\end{gathered}
$$


where

$$
C_{d}(A, Y)=-\beta 1 A-\beta 2 A Y
$$

$C_{U T}(Y)=$ User Operating Cost $(\$ / \mathrm{yr})$ as a function of output $(Y)$;

$T_{U}(Y)=$ User Transfer Costs $(\$ / \mathrm{yr})$;

$C_{U N}(Y)=$ Net User Costs $(\$ / \mathrm{yr})$;

$C_{g}=$ Cost of Gas $(\$ / \mathrm{km})$;

$C_{o}=$ Cost of Oil $(\$ / \mathrm{km})$;

$C_{t}=$ Cost of Tires $(\$ / \mathrm{km})$;

$C_{f}=$ Cost of fire and theft (insured) $(\$ / \mathrm{yr})$;

$C_{p}=$ Cost of property damage and liability (insured) $(\$ / \mathrm{yr})$;

$C_{c}=$ Cost of collision (insured) ( $\left.\$ / \mathrm{yr}\right)$;

$C_{l}=$ Cost of licenses, fees, and taxes $(\$ / \mathrm{yr})$;

$C_{d}(A, Y)=$ Cost of depreciation $(\$ / \mathrm{yr})$ as function of years and output;

$Y=$ Output in distance traveled per year $(\mathrm{km})$;

$A=$ Age (years over which car is depreciates), for purposes of our analysis $A=1$ when

determining annual depreciation;

$\beta 1, \beta 2=$ coefficients from price model discussed in the following section.

Since we are dealing with a single output product, vehicle trips, we can apply basic economics to find the average and marginal costs per unit distance $(Y)(\mathrm{km})$ :

$$
\begin{gathered}
A C_{U N}=C_{U N} / Y=C_{g}+C_{o}+C_{t}-\beta 1 A / Y-\beta 2 A \\
M C_{U N}=\partial C_{U N} / \partial Y=C_{g}+C_{o}+C_{t}-\beta 2 A
\end{gathered}
$$

where $A C_{U N}=$ Average Unit Cost; $M C_{U N}=$ Marginal Cost.

The hypothesis of the user cost model is that the cost of depreciation increases with age and distance traveled.

\subsection{Results}

It is known that depreciation occurs for two main reasons: wear and tear on the vehicle and changing demand. Demand for an aging (unused) vehicle is replaced by the demand for a newer vehicle which comes equipped with more technologically advanced features. Demand is also affected by changing preferences. In order to estimate the various cost control components of depreciation, and thus to distinguish between average (stand-alone) cost or the marginal (incremental) cost, we developed a database of used car asking prices from an internet site for used car trading selecting Honda Accords and Ford Tauruses. A model with the following form was estimated using ordinary least squares regression, the results are shown in Table 1.

$$
P=\beta 0+\beta 1 A+\beta 2 A Y+\beta 3 M
$$

where $P=$ asking price (current \$); $A=$ Age of automobile=1996, Model Year; $Y=$ Distance Traveled per Year (miles) for that particular car; $M=$ Make 1 if the car was a Ford Taurus, 0 if it was a Honda Accord; $\beta x=$ model coefficients.

Table 1. Car price model estimation

\begin{tabular}{lcccc}
\hline Variables & Coefficients & Standard error & $t$ stat & $p$ value \\
\hline$\beta 0$, constant & 20053 & 758 & 26.44 & 0.00 \\
$\beta 1, A$ & -1351 & 201 & -6.69 & 0.00 \\
$\beta 2, A Y$ & -0.0234 & 791 & -1.53 & 0.13 \\
$\beta 3, M$ & -2738 & & -3.46 & 0.00 \\
Statistics & & & \\
Adjusted R square & 0.861 & & \\
Standard error & 1858 & & \\
Observations & 34 & & \\
\hline
\end{tabular}


The implication of this is that the car loses $\$ 0.023 / \mathrm{vmt}$ in value and loses $\$ 1351$ in value per year. This also implies that Tauruses sell for $\$ 2740$ less than Hondas, all other things being equal. The intercept term suggests that a new Honda Accord (1996) with no miles is valued at $\$ 20,053$. These are not actual transaction prices, but asking prices so we can probably assume that an additional $10-20 \%$ markup is included in the price. For a car that is driven $16,000 \mathrm{~km}$ per year, the model gives a depreciation of $\$ 1581$. Even considering markup, these are less than the depreciated values of $\$ 2883$ given by the American Automobile Association AAA, (1993). Used cars suffer the problem of adverse selection, so prices may tend to underestimate their actual value because of the possibility of 'lemons'. The buyer offers a price lower than what he would pay if he were certain that the car is good.

\subsection{Average and incremental costs}

There are two ways to estimate operating costs: stand-alone (average) costs or incremental (marginal) costs. In our case, stand-alone costs reflect the cost of owning the car and are predicated upon the assumption that intercity travel is not only routine but that it is also one of the primary reasons for owning the car. The incremental cost assumes that the car is already owned (or leased or rented), and that only the incremental cost of making the trip (ignoring a large part of the depreciation for instance) should be counted. The efficient answer can be determined in principle by Ramsey pricing, which requires knowing the inverse elasticity of demand, and should fall between the stand-alone and incremental costs. Applying eqns (5) and (6) above, and assuming values for costs (described below) we compute the average unit costs and average incremental or marginal cost of car ownership, shown in Table 2.

For a $1000 \mathrm{~km}$ trip, the average cost for the automobile user is $\$ 130$, but the marginal cost is only \$49. In all likelihood, the user perceives the cost of the trip as the marginal cost, if not lower, since he is likely to disregard the cost of oil, tires and depreciation from his calculation.

\subsection{The cost of a rented car}

The cost of a highway trip can also be estimated by considering the cost of car rental. This is important not only for individuals who do not own a car, but also for visitors who enter the area via air (or rail) and visit multiple cities within the area. For a single trip, the stand alone user cost of a rental is the same as the incremental cost of rental.

When a car rental company rents out a vehicle, it can amortize the fixed costs of ownership over a much larger number of miles than the typical driver would undertake. This price advantage is mitigated somewhat by overhead costs which must be covered by the firm. The cost of renting an intermediate car for a three-day weekend is about $\$ 90-120$. If we assume that a $1000 \mathrm{~km}$ trip can be made over the weekend, then the rate for the car is $\$ 0.09-0.12 / \mathrm{vkt}$ in charges plus $\$ 0.015 / \mathrm{vkt}$ for gas, excluding oil, maintenance and tires. Excluding the cost of gas, the rental cost is less then the average unit cost of ownership, but more than the $\$ 0.05 / \mathrm{vkt}$ marginal cost of ownership. So the cost clearly depends on the basis over which it is taken.

\subsection{Comparisons of user costs}

The AAA (1993) estimates a series of unit costs for transportation, including a gas cost of $\$ 0.036 /$ vkt, excluding tax. However, the retail price of a gallon of gas (excluding tax) at the end of

Table 2. Average unit and incremental cost of car ownership*

\begin{tabular}{lc}
\hline Variable & Value \\
\hline$C g$, Cost of gas $(\$ / \mathrm{vkt})$ & $\$ 0.015$ \\
$C o$, Cost of oil $(\$ / \mathrm{vkt})$ & $\$ 0.014$ \\
$C t$, Cost of tires $(\$ / \mathrm{vkt})$ & $\$ 0.0054$ \\
$\beta 1$, Age depreciation $(\$ / \mathrm{yr})$ & $\$ 1351$ \\
$A$, Age (yr) & 1 \\
$Y$, Distance/year $(\mathrm{km})$ & 16,000 \\
$\beta 2$, Distance depreciation $(\$ / \mathrm{vkt})$ & $\$ 0.014$ \\
Average unit cost $(\$ / \mathrm{vkt})$ & $\$ 0.130$ \\
Marginal cost $(\$ / \mathrm{vkt})$ & $\$ 0.049$ \\
Rental cost $(\$ / \mathrm{vkt})$ & $\$ 0.120$ \\
\hline
\end{tabular}

*Assuming 1.5 passengers/vehicle. 
1995 is about $\$ 0.70 /$ gallon though noticeably higher in 1996 . At 28 miles per gallon, the Corporate Average Fuel Economy standard for new cars, which all manufacturers must achieve as a fleet average, this translates to $\$ 0.015 / \mathrm{vkt}$ for gas. The cost for gas and oil we use are close because we remove special excise taxes from the price of gas (we consider them a transfer to infrastructure), while we include general taxes on oil in the price. We adopt the AAA (1993) estimates for the price of oil and maintenance and tires. As noted above, we estimated depreciation ourselves, and found a lower level than that given by AAA. Our three estimates for average unit costs, marginal cost, and rental cost are summarized at the bottom of Table 2 .

\section{INFRASTRUCTURE COSTS}

\subsection{A model of infrastructure costs}

We want to estimate a model predicting total expenditures on infrastructure as a function of price inputs (interest rates, wage rates, and material costs), outputs (distance traveled by passenger vehicle, single unit truck, and combination truck ), and network variables (the length of the network, the average width of links). We also want to distinguish between long run and short run total expenditures. The difference between the short and long run model is like the variable returns to scale models in economics where capital is considered fixed when one is estimating a short run cost model. Once capital is allowed to vary we move into the long run.

The hypothesis of the expenditure model is that total expenditures increase with outputs, with prices, and with the size of the network, so all signs should be positive. However, the amount of increase with output depends on the nature of the output.

5.1.1. Total Expenditures. Total expenditures data are developed from two sets of information: data compiled by the Federal Highway Administration on maintenance, operating, and administrative costs (FHWA, 1993); and capital stock data collected by Gillen et al. (1994). The capital stock series was inflated from 1988 to 1993 levels (a 20\% inflation was taken), and then was discounted to reflect an annualized cost. The annual cost was assumed to equal the total cost multiplied by the price of capital or interest rate - a state with a higher interest rate will has a higher opportunity cost for investing money in fixed assets. The annualized capital cost $\left(C_{k}\right)$ was added to annual expenditures on maintenance $\left(C_{m}\right)$ and operations and administration $\left(C_{l}\right)$ to create an estimate of long run total expenditures $\left(T E_{L R}\right)$. The short run total expenditures $\left(T E_{S R}\right)$ assumes that the stock of capital is fixed in the short term (though it varies in the long term), and thus looks at the allocation of costs for maintenance and labor. Total expenditures are reported in thousands of dollars and summarized in Table 3.

5.1.2. Outputs. Three classes of output $(Y)$ are defined from the FHWA Highway Statistics Report (1993): passenger cars $\left(Y_{a}\right)$, single unit trucks $\left(Y_{s}\right)$, and combination trucks $\left(Y_{c}\right)$ in millions of vehicle miles traveled per year and summarized in Table 4. Because of their relative damage to the roadway, costs associated with passenger cars are expected to be less than those associated with single unit trucks, which is less still than those associated with combination trucks. However,

Table 3. Expenditures data

\begin{tabular}{|c|c|c|c|c|c|c|c|}
\hline & $\begin{array}{c}\text { SC stock } \\
\text { capital } 1988 \\
\text { (U.S. } \\
\text { \$millions) }\end{array}$ & $\begin{array}{c}\text { Capital } \\
\text { expenditure } \\
1993 \text { (U.S. } \\
\text { \$thousands) }\end{array}$ & $\begin{array}{l}\mathrm{Cm} \\
\text { maintenance } \\
\text { expenditure } \\
1993 \text { (U.S. } \\
\text { \$thousands) }\end{array}$ & $\begin{array}{c}\text { C11 } \\
\text { administrative } \\
\text { expenditure } \\
1993 \text { (U.S. } \\
\text { \$thousands) }\end{array}$ & $\begin{array}{l}\text { C12 law safe } \\
\text { expenditure } \\
1993 \text { (U.S. } \\
\text { \$thousands) }\end{array}$ & $\begin{array}{c}\text { Interest } \\
1993 \\
\text { (thousands) }\end{array}$ & $\begin{array}{c}\text { Bond } \\
\text { retirement } \\
1993 \text { (U.S. } \\
\text { Sthousands) }\end{array}$ \\
\hline Average & 10457.72 & 588,205 & 137,505 & 143,064 & 138,985 & 70,994 & 89,979 \\
\hline
\end{tabular}

Table 4. Outputs data

\begin{tabular}{lccccc}
\hline & $\begin{array}{c}\text { Ya auto VMT } \\
\text { (millions) }\end{array}$ & $\begin{array}{c}\text { Ys single truck } \\
\text { VMT (millions) }\end{array}$ & $\begin{array}{c}\text { Yc combination truck } \\
\text { VMT (millions) }\end{array}$ & \%Urban & \%Freeway \\
\hline Average & 32,738 & 7352 & 4890 & 0.53 & 0.27 \\
\hline
\end{tabular}

Units: VMT $=$ Vehicle Miles Traveled. Model is estimated in English units (miles) and results were converted to SI (km). 
this may not be the case if there are economies of scope associated with roadways. For instance, suppose a network is designed for peak rush hour flows, and that these flows are dominated by passenger cars. In the off-hours, capacity is underutilized. If it is during those hours that trucks use the roadway, then the government expenditure on transportation to serve those trucks may in fact be less than that for passenger vehicles. At a minimum, because these two effects (efficient capacity utilization vs greater damage) are offsetting, the relative additional costs to serve trucks would not be as great as that indicated by an engineering analysis based solely on damage which does not consider scope economies.

5.1.3. Inputs. Several price measures are included in the model. The first, to measure the price of capital $\left(P_{k}\right)$, including the entire built stock of the highway network, is measured by taking the interest rate, which reflects the cost of borrowed money. States with lower bond ratings or higher interest rates must pay more to borrow, and have a higher opportunity cost for fixed investment. We used Moody's ratings for each state (Bureau of Census, 1993) and typical interest rates paid for lower rated bonds garnered from recent offerings to estimate the price of capital.

Second, the price of labor $\left(P_{l}\right)$ is measured by taking the average wage rate of state government employees (normalized to the national average) for 1993 (Bureau of Labor Statistics, 1995). The third main input is the price of materials $\left(P_{m}\right)$. The principal material used in highway construction is bituminous concrete for pavement. We computed indices of construction materials prices by taking the price of an input (FHWA, 1994), and dividing by the national average of the price of that input. The indices, reflecting relative prices, with a mean at 1 , can then be added to create a composite index for construction materials. For instance, the price of bituminous concrete in a state, and divided by the national average of the unit price of bituminous concrete, provides an index representing the relative price of bituminous concrete. The materials for which data was available (bituminous concrete (price per ton), common excavation (price per cubic yard), reinforcing steel (price per pound), structural steel (price per pound), and structural concrete (price per cubic yard) were included in the database. Boske (1988) discusses the data and the use of indices with this data, though only bituminous concrete was used in our final regressions.

5.1.4. Network. We included two variables to describe the network to try to measure economies of density, summarized in Table 5 . The first is the length $\left(N_{l}\right)$ in linear miles of roadway, the second is the width $\left(N_{w}\right)$ the average number of lanes of interstate highways derived from the Highway Statistics Report (FHWA, 1993). While the number of miles of interstate with four lanes and more than four lanes is reported, there is no indication of the number of miles of two lane, three lane, four-lane, etc., non-interstate roads, so assumptions were made. When providing capacity, there is a trade-off between building more skinny facilities or fewer wider facilities. Potentially there is some difference in the cost based on whether the road is urban or rural, so that data was included in the database. We hoped to capture this trade-off by including both network variables.

\subsection{Results}

The models (long run total expenditures and short run total expenditures) are estimated two ways, first using ordinary least squares (OLS) and then using feasible generalized least squares [weighted least squares (WLS)]. WLS, where the reciprocal of variance is used as a weight, corrects for the clear heteroscedasticity in the data, wherein the size of the residual is correlated with the size of the dependent variables. Two functional forms: a linear model and a Cobb-Douglas (using the log of both dependent and independent variables) model were estimated. The results are given below following an examination of the data. The coefficients from the log-linear (Cobb-Douglas) weighted least squares are used for further analysis, the other regression results are available in Levinson et al. (1996) for information purposes.

The model we estimate is restrictive in that it does not allow for the interaction terms between variables. Ideally interaction terms could have been used to capture the relationship between independent variables. Other functional forms, such as translog, which allow for the interaction of

Table 5. Network size data

\begin{tabular}{cccccc}
\hline & L, Total miles & L, \% freeway & L, \% urban & W, \%UrbFwy > four lanes & W, \% RurFwy > four lanes \\
\hline Average & 76,563 & 0.017 & 0.24 & 0.39 & 0.07 \\
\hline
\end{tabular}


Table 6. Long and short run total expenditures results

\begin{tabular}{|c|c|c|c|c|c|c|}
\hline & Long run & & & Short run & & \\
\hline Variable & B & $\mathrm{T}$ & Sig-T & B & $\mathrm{T}$ & Sig-T \\
\hline $\ln (P k)$ & 10.831 & 110.247 & 0.0000 & 0.587 & 0.752 & 0.4575 \\
\hline $\ln (P l)$ & 0.786 & 30.346 & 0.0020 & 0.097 & 0.174 & 0.8630 \\
\hline $\ln (P m)$ & 0.00494 & 0.222 & 0.8257 & -0.071 & -0.594 & 0.5565 \\
\hline $\ln (Y a)$ & 0.439 & 90.824 & 0.0000 & 0.724 & 40.631 & 0.0001 \\
\hline $\ln (Y S)$ & 0.179 & 40.885 & 0.0000 & 0.221 & 10.631 & 0.1121 \\
\hline $\ln (Y c)$ & 0.225 & 50.016 & 0.0000 & 0.00778 & 0.060 & 0.9525 \\
\hline (Constant) & 110.280 & 200.050 & 0.0000 & 50.111 & 20.187 & 0.0357 \\
\hline \multicolumn{7}{|l|}{ Result } \\
\hline Adjusted R square & 0.99527 & & & 0.885 & & \\
\hline Standard error & 0.99311 & & & 0.335 & & \\
\hline $\mathrm{F}$ & 14020.4 & & & 520.4263 & & \\
\hline Significant $\mathrm{F}$ & 0.0000 & & & 0.0000 & & \\
\hline
\end{tabular}

variables were tested, but to date have not provided satisfactory results with this data, though investigation into alternative functional forms is continuing. The degree of accuracy of our estimates is not expected to be too different with alternative forms, the data are not perfect to begin with, and these estimates are, in our opinion, on par with (and probably better than) estimates in other parts of this paper.

Largely, the hypotheses were borne out as shown in Table 6, the signs were generally in the expected direction. Three variables were not significant: $N_{l}$ and $N_{w}$, reflecting the length width of the roadway, and $P m$, the price of materials. To avoid collinearity problems, we dropped $N_{l}$ and $N_{w}$ from the final model. More importantly, there is wide variance around the estimate of the coefficient for $Y_{\mathrm{c}}$, combination trucks. Other regressions, with different sets of independent variables have shown coefficients on $Y_{c}$ about $50 \%$ larger, indicating that the true value is probably higher and collinearity, which is obviously an important factor in this data, may be causing some uncertainty in parameter estimates.

The long $\left(T E_{L R}\right)$ and short $\left(T E_{S R}\right)$ run total expenditures can be expressed as the equations below:

$$
\begin{aligned}
T E_{L R} & =C_{k}+C_{l}+C_{m}=f\left(Y_{a}, Y_{s}, Y_{c}, P_{k}, P_{l}, P_{m}, N_{l}, N_{w}\right)+e \\
& =\beta 0 Y_{a}^{\beta 1} Y_{s}^{\beta 2} Y_{c}^{\beta 3} P_{k}^{\beta 4} P_{l}^{\beta 5} P_{m}^{\beta 6} N_{l}^{\beta 7} N_{w}^{\beta 8}+e=79221 Y_{a}^{0.439} Y_{s}^{0.179} Y_{c}^{0.225} P_{k}^{1.83} P_{l}^{0.786} P_{m}^{0.00492} \\
T E_{S R}= & C_{l}+C_{m}=f\left(Y_{a}, Y_{s}, Y_{c}, P_{k}, P_{l}, P_{m}, N_{l}, N_{w}\right)+e \\
= & \beta 0 Y_{a}^{\beta 1} Y_{s}^{\beta 2} Y_{c}^{\beta 3} P_{k}^{\beta 4} P_{l}^{\beta 5} P_{m}^{\beta 6} N_{l}^{\beta 7} N_{w}^{\beta 8}+e=165.67 Y_{a}^{0.724} Y_{s}^{0221} Y_{c}^{0.0077} P_{k}^{0.587} P_{l}^{0.097} P_{m}^{-0.071}
\end{aligned}
$$

\subsection{Average and marginal costs}

Using the total expenditure functions $\left(T E_{L R}, T E_{S R}\right)$, we can compute marginal cost functions for the three classes of vehicles (i). These are solved for average values [the values for each state are given in Levinson et al. (1996)].

$$
M C_{I i}(Y)=\partial T E(Y) / \partial Y_{i}
$$

Applying the marginal cost equations to the national totals for $Y_{a}, Y_{c}, Y_{s}$ and national average prices, we get the long and short run marginal costs given in Table 7.

Table 7. Long and short run marginal and average incremental infrastructure costs and scale economies

\begin{tabular}{lccc}
\hline & Auto & Single truck & Combination truck \\
\hline Long run marginal & $0.0188(0.0072-0.0331)$ & $0.0431(0.0205-1.33)$ & $0.0514(0.0193-0.1349)$ \\
Long run average incremental & 0.017 & 0.063 & 0.101 \\
$\mathrm{~S}=\mathrm{IC} / \mathrm{MC}$ & 0.92 & 1.45 & 1.96 \\
Long run economies of scale & Decreasing & Increasing & Increasing \\
Short run marginal & 0.0055 & 0.0075 & 0.0003 \\
Short run average incremental & 0.00075 & 0.0298 & 0.0032 \\
$\mathrm{~S}=$ AIC/MC & 0.14 & 3.97 & 10.67 \\
Short run economies of scale & Decreasing & Increasing & Increasing \\
\hline
\end{tabular}

Unit: \$/vkt. Parentheses refer to range of state level highway agency costs. 
The average cost function is well defined for the single output but, under the definition of a vector of flows the measure of average costs does not uniquely exist, unless the outputs in the vector $Y$ are assumed to be equivalent or systematically related. Some type of index must be used in place of the vector $Y$ in the calculation of an 'average' cost. In this way, the calculation of average cost requires a weighting of the outputs. The incremental cost of introducing the additional output (vector of flows) $Y_{n}$ is equal to:

$$
\mathbf{I C}_{\mathbf{I n}}=T E(Y)-T E\left(Y_{m-n}\right)
$$

where $Y=\left\{Y_{1}, s, Y_{m}\right\}$

$$
\begin{aligned}
Y_{n} & =\left\{Y_{1}, s, Y_{n}\right\} \\
Y_{m-n} & =\left\{Y_{n+1}, s, Y_{m}\right\}
\end{aligned}
$$

To estimate the incremental cost, we can thus evaluate the total expenditure function at two values. For example, to estimate $\mathrm{IC}_{\mathrm{aLR}}$, the long run incremental cost per unit of automobile travel (1000 vehicle miles traveled), we can evaluate at the means for all values except Ya, which we evaluate at the mean $\left(E\left(Y_{a}\right)\right)$ and at 1 (and then convert to SI units).

$$
I C_{a L R}=\left(E\left(Y_{a}\right)^{0.439}-1^{0.439}\right)\left(79221 P_{k}^{1.83} P_{l}^{0.786} P_{m}^{0.00492} Y_{c}^{0.225} Y_{s}^{0.179}\right) / E\left(Y_{a}\right)=\$ 0.017 / \mathrm{vkt}
$$

A similar exercise is undertaken for short run incremental costs. The results for all three vehicle types over both the long and short run are shown in Table 7.

\subsection{Economies of scale and scope}

With economies of scale, the cost of producing more transportation output within the same network is lower for larger levels of output. The economic interpretation of economies of scale $(S)$ is the ratio of average costs (or in the multi-product case, incremental costs) to marginal costs. Where $S$ is greater than one, there are economies of scale, where $S$ is less than one there are diseconomies of scale.

Prior to determining economies of scale in this multi-product case, the measure of economies of scale for each output, or the product specific economies of scale, must be examined. Small et al. (1989) reported the existence of significant economies of scale associated with the durability output of roads, the ability to handle axle loads. This is because the pavement's ability to sustain traffic increases proportionally more than its thickness. They also found evidence that there are slight economies of scale in the provision of road capacity; i.e. the capacity to handle traffic volume. However, they reported diseconomies of scope from the joint production of durability and capacity because as the road is made wider to accommodate more traffic, the cost of any additional thickness rises since all the lanes must be built to the same standard of thickness. They conclude that these three factors together result in highway production having approximately constant returns to scale. In other words, the output-specific scale economies are offset by the diseconomies of scope in producing them jointly.

We find that there are economies of scale for trucks, and diseconomies of scale for passenger cars (as shown in Table 7). This suggests complementarities in the provision of infrastructure, probably explained by the peaked nature of capacity requirements for cars as compared with trucks, which offsets the requirements for thicker pavement. Cars, which are used relatively more intensively in the already congested peak period, impose a higher marginal cost than average cost on infrastructure. The next infrastructure expansion will cost more than previous expansions, as many roads already take advantage of the easy opportunities for expansion, any additional construction costs will require land acquisition in already developed (and therefore more expensive) areas.

\subsection{Comparison of infrastructure costs}

We can compare the econometric approach taken above with other studies. Miller and Moffet (1993) calculate total annual road capital and operating expenses attributable to cars as $\$ 85.7$ billion per year, including $\$ 48$ billion of pavement wear costs, $\$ 24.8$ billion of other maintenance, and $\$ 12.6$ billion of expansion and construction costs. They subtract road user fees from cars and light trucks of $\$ 21.5$ billion, and estimate an annual capital and operating cost of $\$ 64$ billion per year or $\$ 0.0087 /$ vkt. To estimate the full cost, not including user payments (which are simply 
transfers), application of their methodology produces an estimate of $\$ 0.011 / \mathrm{vkt}$ average cost, which is about $50 \%$ lower than our estimate of $\$ 0.017 / \mathrm{vkt}$ long run average cost and $\$ 0.019 / \mathrm{vkt}$ marginal cost. Obviously the methodologies are dissimilar, which explains the difference in part. We take an econometric approach. They adopt a crude engineering approach, but extrapolate the results to the national system. Furthermore, they adopt FHWA (1982) cost estimates of pavement wear as a fixed \$/ESAL-mile, with passenger cars responsible for 0.05 ESAL per mile. However the damage per mile is non-linear function of axle-loadings, ESALs increase with the third or fourth power of axle-loading depending on pavement wear (Small et al., 1989). This suggests that the amount of pavement damage attributed to automobiles by the Miller and Moffet (1993) study is significantly overstated.

\section{TIME COSTS}

The time which a trip takes can be divided into two components, uncongested and congested times. The uncongested time is a simple function of distance and uncongested speed, and is clearly an internal cost. Congested time depends on the number of other vehicles on the road, and thus is external to the vehicle but internal to the transportation system.

The exact relationship between volume and delay can be best determined by a detailed, site specific, engineering study. For highways, the Highway Capacity Manual (Transportation Research Board, 1985) provides some estimates. For a segment with a $70 \mathrm{mph}$ (112 kph) design speed, under ideal conditions the capacity $\left(Q_{h o}\right)$ is taken to be 2000 passenger cars per hour per lane (pcphpl). The following is an equation for limited access freeways derived from the data given in HCM, (1985) and graphed in Fig. 1.

$$
\begin{gathered}
T C_{T}=Q_{h} L / V_{f}+0.32 *\left(Q_{h}\right)\left(Q_{h} / Q_{h o}\right)^{10} \\
M C_{T}=\partial T C_{T} / \partial Q=L / V_{f}+3.5 *\left(Q_{h} / Q_{h o}\right)^{10} \\
A C_{T}=L / V_{f}+0.32 *\left(Q_{h} / Q_{h o}\right)^{10}
\end{gathered}
$$

where $T C_{T}=$ Total Cost in vehicle minutes of highway time per vehicle-km; $M C_{T}=$ Marginal Cost in vehicle minutes of highway time per vehicle-km; $A C_{T}=$ Average Cost in vehicle minutes of highway time per vehicle-km; $L=$ Length $(\mathrm{km}) ; V_{f}=$ freeflow speed (km per min); $Q_{h}=$ highway flow in vehicles per hour per lane; $Q_{h o}=$ highway maximum flow (capacity), (2000 vehicles per hour per lane).

The incremental delay caused by an additional vehicle, at capacity (moving from 1999 to 2000 vehicles per hour) can be calculated to be almost 4 min of total delay on a single $1 \mathrm{~km}$ segment. Of course, any estimates of the amount of delay depend on estimates of volume, and vice versa, so the problems will need to be treated together before a definitive answer can be determined.

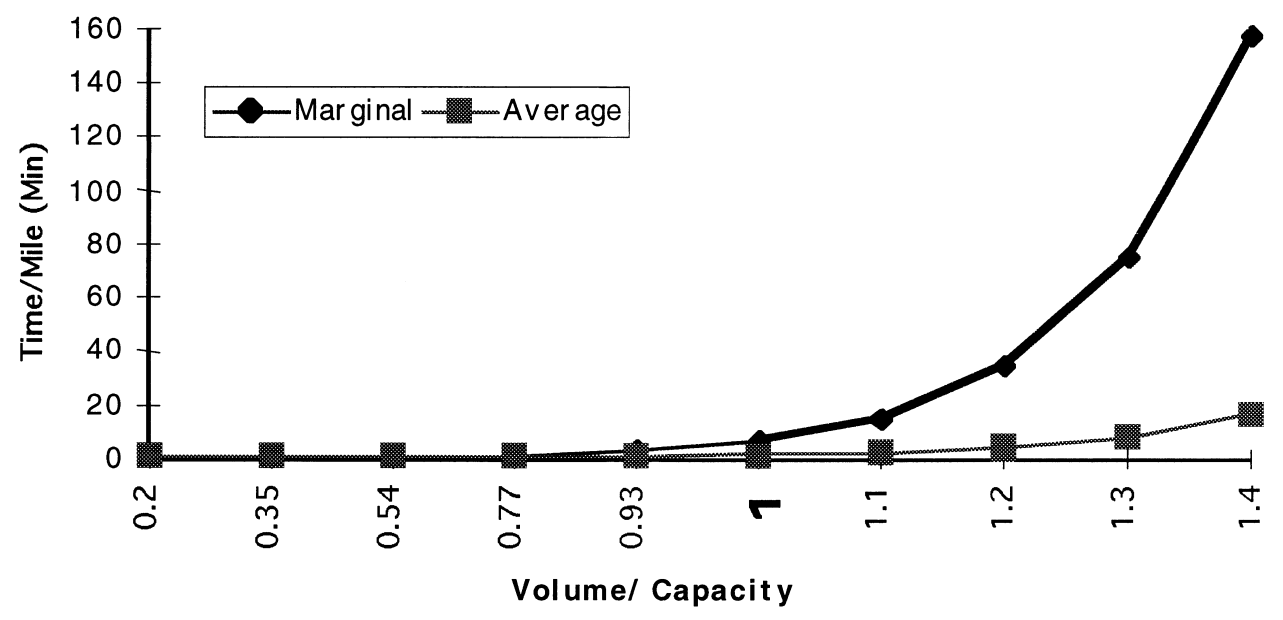

Fig. 1. Congestion: average vs marginal costs of highway travel. 
The value of time depends on factors including mode of travel, the time of day, the purpose (business, non-business) of the trip, the quality or level of service of the trip (including speed), and the specific characteristics of the trip-maker, including income (Hensher, 1995). Furthermore, the value of time saved probably depends on the amount of time saved -60 people saving 1 min may not be worth the same as 1 person saving $60 \mathrm{~min}$. Time in motion is valued differently than time spent waiting. Unexpected delays are more costly than the expected, since those are built into decisions. All of these factors need to be considered in a detailed operational analysis of the costs of travel time and congestion. There are a number of approaches for valuing travel time, ranging from utility theory to theories of marginal productivity (Federal Aviation Administration, 1989). Conservatively, we have adopted a $\$ 10 / \mathrm{h}$ value of time for all trips, though it is easy to see how the monetized costs of time change with changes in this value.

Congestion costs, assuming an average traffic level of 1500 vehicles per hour per lane, at $\$ 10 / \mathrm{h}$ value of time and 1.5 persons per car (delay victims) result in a marginal cost $\$ 0.049 / \mathrm{vkt}$ imposed on other travelers and an average cost of $\$ 0.0045 / \mathrm{vkt}$ suffered by the vehicle driver and passenger.

Freeflow costs can be calculated making assumptions about speed and value of time. If we take a speed of $100 \mathrm{kph}$, and a value of time of $\$ 10$ per hour and 1.5 persons per vehicle, this amounts to an average of $\$ 0.15 / \mathrm{vkt}$ separate from congestion costs. For intercity travel, freeflow costs outweigh congestion costs.

\section{ACCIDENTS}

There are a number of sources recording highway accidents. The National Highway Traffic Safety Administration has two databases: NASS, the National Accident Sampling System and FARS, the Fatal Accident Reporting System. In addition, each state keeps records, as does the insurance industry with its National Council on Compensation Insurance DCI (Detailed Claims Information) database. Injuries are typically classified according to whether they are fatalities and the degree of injury or property damage. While many crashes, particularly minor accidents without loss of life or major injury, are not reported to the police or insurance industry for obvious reasons, we proceed with reported accidents.

Sullivan and Hsu (1988) have estimated the rate of accidents as a function of traffic in California, shown in Table 8. The dependent variable is the square root of the total number of annual accidents in the section during the peak periods 5:00-9:30 a.m. or 3:00-7:30 p.m. It should be noted that while there are more accidents proportionately in urban areas, the share of fatal accidents is much less than in rural areas, as urban accidents tend to be at lower speed. While accidents are often assumed to be a fixed rate, this 'linearity' conjecture should not be assumed to be true.

The principal means for estimating the cost of accidents is to estimate their damage costs. The method employed here is a comprehensive approach which includes valuing years lost to the accident as well as direct costs. Several steps must be undertaken: converting injuries to years of

Table 8 . Square root of total annual accidents during peak periods

\begin{tabular}{|c|c|c|c|}
\hline Independent variables & Description & $\begin{array}{c}\text { Total annual accidents } \\
\text { during peak periods } \\
\text { Coefficient }\end{array}$ & $T$-statistic \\
\hline $\mathrm{L}^{*} \mathrm{~N}$ & $\begin{array}{l}\text { The section length }(\mathrm{L}) \text { in miles times the number of } \\
\text { travel lanes }(\mathrm{N}) \text { (excluding auxiliary lanes) }\end{array}$ & 0.19 & 3.90 \\
\hline IRAMP & The average number on-ramps per mile & 1.92 & 6.63 \\
\hline ARAMP & $\begin{aligned}= & \text { IRAMP if there are auxiliary lanes }=0 \text { if there are } \\
& \text { no auxiliary lanes in the section }\end{aligned}$ & -0.098 & -4.10 \\
\hline Qh & $\begin{array}{l}\text { The average hourly traffic volume in all lanes during } \\
\text { the peak period }\end{array}$ & 0.000143 & 3.90 \\
\hline None & $\begin{array}{l}\text { The average percentage of time during the peak period } \\
\text { when no queue exists in the freeway section }\end{array}$ & -0.017 & -3.38 \\
\hline $\mathrm{N}$ & $\begin{array}{l}\text { The average percentage of time during the peak period } \\
\text { when no queue exists in the freeway section }\end{array}$ & 62 & \\
\hline R squared & & 0.95 & \\
\hline
\end{tabular}


life, developing a value of life, and estimating other costs. Placing a value on injury requires measuring its severity. Miller (1992) describes a year of functional capacity (365 days/y, 24 h/day) as consisting of several dimensions: Mobility, Cognitive, Self Care, Sensory, Cosmetic, Pain, Ability to perform household responsibilities, and Ability to perform wage work and calculates the number of years of functional years lost by degree of injury. Central to the estimation of costs is an estimate of the value of life, which Miller (1992) summarizes from a number of studies. We use \$2.7 million as the standard value here.

After converting injuries to functional years lost, combining with fatality rates, and value of life, a substantial portion of accident costs have been captured. But this data must be supplemented by other costs, including hospitalization, rehabilitation, and emergency services. The comprehensive costs can be allocated to the various accident categories by severity. Costs vary by location, crashes on urban interstates cost about $\$ 70,000$ while those on rural interstates about $\$ 120,000$ (Miller, 1992).

Application of the Sullivan and Hsu (1988) accident model gives the following results. The average annual total accident rate per hour is 2.214 at a flow $Q_{h}=6000 \mathrm{vph}$ and assuming: $1 \mathrm{~km}$ section, four lanes wide, 0.12 intersections per $\mathrm{km}$, and no queueing. Dividing by 365 (days per yr), and then multiplying by $33 \%$ (the proportion of $41 / 2 \mathrm{~h}$ peak period traffic in the peak hour), and dividing by the number of vehicles, we get the probability of an accident per hour per vehicle is 0.00000034 . Multiplying this by the cost of an accident $(\$ 120,000$ for an rural crash and $\$ 70,000$ as the cost of an urban crash), we get $\$ 0.040 / \mathrm{vkt}(\$ 0.026 / \mathrm{pkt})$ for rural travel or $\$ 0.023 / \mathrm{vkt}$ $(\$ 0.015 / \mathrm{pkt})$ for urban travel.

The average amount paid per year in insurance for collision, property damage, and liability, given by AAA (1993) was $\$ 617$ per year. This ranges between $\$ 0.025 / \mathrm{pkt}$ at $24,000 \mathrm{~km} / \mathrm{yr}$ and $\$ 0.038 / \mathrm{pkt}$ at $16,000 \mathrm{~km} / \mathrm{yr}$. Given that some fraction of insurance costs paid by users result in profit to the insurers, the cost estimates are very similar to the total costs of accidents, and confirms our decision to treat insurance as a transfer.

\section{NOISE}

The damages caused by noise include the loss of sleep, lower productivity, psychological discomfort and annoyance. These are hard to quantify, but because they are associated with a place, the quantity of damage is often viewed as resulting in lower property values. A number of studies have been performed over the years to measure the decline in residential property value due to noise and its associated vibration. This has not been done for non-residential (commercial and public) buildings, however, where abatement measures are more cost-effective.

Hedonic models of housing collected by Modra and Bennett (1985), Nelson (1982), and from other studies are summarized in Levinson et al. (1996). These studies use a noise depreciation index (NDI) which is the percentage reduction of house price per $\mathrm{dB}(\mathrm{A})$ above some base. To determine the amount of noise damage produced by a facility, one must know the noise produced on that facility (as a function of traffic flow) and the location of residences near the facility. Also the house value must be known because the impact of noise is generally found to be a percentage reduction in house price rather than a fixed value. The average NDI for all of the noise surveys since 1967 is 0.62 , giving us some confidence in using that number as the noise depreciation index for this analysis.

The damage caused by a new highway is determined by comparing the noise before and after the roadway is deployed, in our analysis we assume a baseline of background noise exposure forecast (an index of noise in $\mathrm{dB}(\mathrm{A})$ weighted by number of events over a time period) (NEF) of 30. The model is solved by dividing the area on each side of the road into $10 \mathrm{~m}$ strips (s) parallel to the road. Each $10 \mathrm{~m}$ by one $\mathrm{km}$ strip has a number of housing units $\left(H_{S}\right)$ depending on the density. The total damage for each strip is computed based on multiplying the homes by the value $\left(V_{H}\right)$ of each home by the noise depreciation index (NDI) by the net increase in the NEF [after $\left(\mathrm{NEF}_{\mathrm{a}}\right)$-before $\left(\mathrm{NEF}_{\mathrm{b}}\right)$ ]. The total damage is converted to a present cost and is summed over all the $10 \mathrm{~m}$ strips for a $1 \mathrm{~km}$ stretch.

To estimate the full cost of noise per passenger $\mathrm{km}$ traveled, we need to convert the total change in the prices of homes as a result of noise damage into an annual charge. The total damage is then amortized over a number of years $(n)$, which we take to be 30 , at the assumed discount rate (i) of 
$7.5 \%$. For automobile travel the integrated highway noise model gives a range of between $\$ 0.0001 /$ vkt and $\$ 0.0060 / \mathrm{vkt}$ average cost, depending on flow, given the other assumptions of Home Value $=\$ 250 \mathrm{~K}$, Density $=360 \mathrm{HH} / \mathrm{sqkm}$, Cost $/ \mathrm{dB}(\mathrm{A})=0.0062$, a speed of $100 \mathrm{~km} / \mathrm{h}, 10 \%$ heavy vehicles, and a maximum range of $500 \mathrm{~m}$ on each side of the highway. This charge can then be divided by the total passenger volume per yr to develop the charge per passenger $\mathrm{km}$. We use the a capital recovery equation in the model to convert net present value to an annualized cost.

A regression was performed after fixing the assumptions noted above, with the independent variable being the natural $\log$ of highway flow $\left(Q_{h}\right)$, and the dependent variable being the average cost in $\$ /$ vkt. It should be noted that the average cost of noise depends not only on same direction flow, but also on opposite directional flow, complicating this problem. Some of the variables can be re-incorporated into the model through the use of multiplicative adjustment factors for density $\left(f_{D}=\right.$ Density $/ 360($ default $\left.=1)\right)$, House Value $\left(f_{H}=\right.$ House Value $\$ \$ 250,000($ default $\left.=1)\right)$, and the Cost per decibel deflator $\left(f_{C}=\right.$ Cost per $\mathrm{dB}(\mathrm{A}) / 0.0062($ default $=1)$ ). The average cost function was estimated $\left(r^{2}=0.92\right.$, number of observations $\left.=15\right)$, and from it the total cost and marginal cost expressions were derived, all three are given below.

$$
\begin{gathered}
A C_{N}=f_{D} * f_{H} * f_{C}\left(-0.018+0.0028 \ln \left(Q_{h}\right)\right) \\
T C_{N}=Q_{h} * A C_{N}=f_{D} * f_{H} * f_{C}\left(-0.018 Q_{h}+0.0028 Q_{h} \ln \left(Q_{h}\right)\right) \\
M C_{N}=\partial T C_{N} / \partial Q_{h}=f_{D} * f_{H} * f_{C}\left(-0.018+0.0028 *\left(1+\ln \left(Q_{h}\right)\right)\right)
\end{gathered}
$$

A graph of $\$ /$ vkt vs flow is shown on Fig. 2. However this value is extremely sensitive to assumptions. At an auto occupancy of 1.5 and flow of 6000 vehicles per hour, this converts to $\$ 0.0045 /$ pkt.

To compare, IWW/INFRAS (1995) gives noise estimates from Europe of $\$ 0.0058 /$ pkt for automobiles, about the same for buses $(\$ 0.0054 / \mathrm{pkt})$ and $\$ 0.0163 / \mathrm{tkt}$ (tonne $\mathrm{km}$ traveled) by truck. Miller and Moffet (1993) report a range from $\$ 0.0008 /$ pkt to $\$ 0.0013 /$ pkt urban based on various studies, in 1990 U.S. dollars.

\section{AIR POLLUTION AND GLOBAL CHANGE}

Recent work on the costs of air pollution from cars comes from Small and Kazimi (1995) analyzing the Los Angeles region. They update air pollution emission factors from the EMFAC, (California Air Resources Board, 1991) model to correct for reported underestimation of pollution. They then review recent evidence on mortality and morbidity and its association with pollutants (VOC, PM10, SOx, NOx). They combine various exposure models of the Los Angeles region with health costs Their findings suggest that particulate matter is a primary cause of mortality and morbidity costs, followed by morbidity due to ozone. Of course, costs in densely populated areas, such as the Los Angeles basin, should be higher than in rural areas as the exposure rate is far

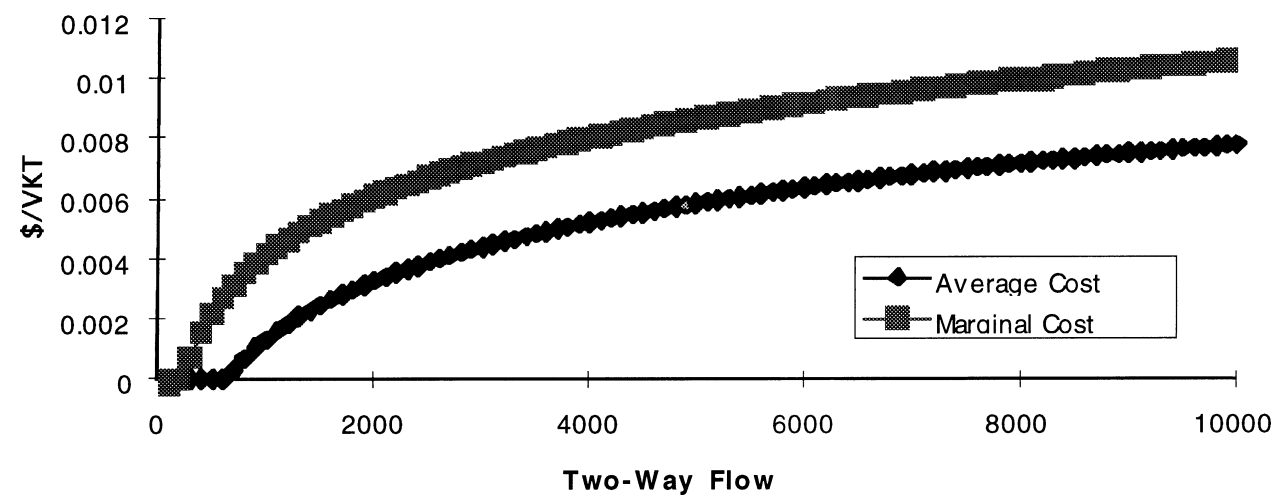

Fig. 2. Highway noise: average and marginal costs. 
higher. While they also assume a value of life of $\$ 4.87$ million in their baseline assumptions, we report their estimate using a $\$ 2.7$ million value of life $\left(V_{L}\right)$ for consistent comparison with other studies and our accident costs. A review of the literature on material and vegetation damages suggests that those cost components are small compared with the costs of health damages.

The use of a macro-economic/global climate model to estimate a 'carbon tax' which would be the price of damages from pollution has been attempted by Nordhaus (1994). He developed a model which estimates the appropriate tax (per ton of carbon equivalent) at a given point of time to optimize the amount of pollution, trading off economic costs of damages due to greenhouse gases and the damages due to imposing the tax. For 1995, his model estimates an appropriate tax of $\$ 5.29 /$ ton $C$.

Performing the calculations combining emission rates and damages per unit of emission with the data reported in Table 9, our estimate of local air pollution cost is $\$ 0.0053 / \mathrm{vkt}$ ( $\$ 0035 / \mathrm{pkt}$ ), while the global environmental impact cost is $\$ 0.0003 / \mathrm{vkt}(\$ 0.0002 / \mathrm{pkt})$. To compare, these costs tend to be on the low end of pollution and climate change cost estimates. Miller and Moffett (1993) calculate car and light truck pollution costs to be about $\$ 0.024 / \mathrm{pkt}-\$ 0.042 / \mathrm{pkt}$. This is 10 times higher than our estimate. Their estimates for the cost of carbon dioxide emissions is almost 20 times more than ours. Other pollutant cost estimates were higher, and more pollutants were priced, including CFCs, which are being phased out. A summary of estimates of air pollution costs by IBI (1995), ranges from $\$ 0.0015 /$ pkt-\$0.026/pkt. IWW/INFRAS (1995) estimates the external cost of climate change for cars at E0.0066/pkt (ECU) using a $\$ 52.80 /$ tonne proposed carbon tax, while Miller and Moffett assume a carbon tax of $\$ 82.80 /$ tonne- $\$ 179.40 /$ tonne.

\section{COMPOSITE COSTS}

Finally, we assemble the cost for all of the cost categories, after being careful not to double count, and produce our estimates in Table 10. The total long run average cost is $\$ 0.34$ per vehicle $\mathrm{km}$ traveled, including user fixed and variable costs, the cost of time to both the driver and passenger in traveling and in congestion, the cost of accidents, the cost of pollution and the cost of noise.

The importance of this study is not simply in having a base of solid cost estimates, but to provide a framework for comparing the cost components to isolate which are more important and which have the greatest uncertainties.

Table 9. Air pollution and global change costs of highway travel

\begin{tabular}{lccc}
\hline Pollutant & Health damage $(\$ / \mathrm{kg})$ & Auto emissions $(\mathrm{gm} / \mathrm{vkt})$ & Cost $(\$ / \mathrm{vkt})$ \\
\hline PM10 & $\$ 12.85$ & 0.0066 & $\$ 0.000085$ \\
SOx & $\$ 13.82$ & 0.0228 & $\$ 0.000315$ \\
HC & $\$ 1.71$ & 2.254 & $\$ 0.003850$ \\
CO & $\$ 0.0063$ & 7.8 & $\$ 0.000049$ \\
NOx & $\$ 1.33$ & 0.756 & $\$ 0.001000$ \\
Carbon & $\$ 0.0058$ & 46 & $\$ 0.000260$ \\
Total & & & $\$ 0.0056$ \\
\hline
\end{tabular}

Source: Emissions: Small and Kazimi (1995); Damage Costs: Small and Kazimi (1995); Nordhaus (1994). Value of life $=\$ 2.7$ million.

Table 10. Average and marginal long and short run costs by category

\begin{tabular}{lcccc}
\hline Cost category & $\begin{array}{c}\text { Short run marginal } \\
\text { cost }(\$)\end{array}$ & $\begin{array}{c}\text { Short run average } \\
\text { cost }(\$)\end{array}$ & $\begin{array}{c}\text { Long run marginal } \\
\text { cost }(\$)\end{array}$ & $\begin{array}{c}\text { Long run average } \\
\text { cost }(\$)\end{array}$ \\
\hline User fixed + variable & 0.049 & 0.130 & 0.049 & 0.130 \\
Infrastructure & 0.0055 & 0.00075 & 0.019 & 0.0174 \\
Freeflow time & 0.15 & 0.15 & 0.15 & 0.15 \\
Congestion & 0.049 & 0.0045 & 0.049 & 0.0045 \\
Accidents & 0.035 & 0.031 & 0.035 & 0.031 \\
Noise & 0.009 & 0.006 & 0.009 & 0.006 \\
Air pollution & 0.0056 & 0.0056 & 0.0056 & 0.0056 \\
Total & 0.30 & 0.33 & 0.32 & 0.34 \\
\hline
\end{tabular}

Unit: \$/vkt 
While the marginal cost of infrastructure is higher than the average cost, indicating that new construction is increasingly expensive, the marginal cost of driving (user fixed and variable costs) is less than the average cost, indicating that by increasing travel the user can spread his fixed cost of a vehicle over more trips without penalty while paying a fairly low marginal cost of $\$ 0.049 / \mathrm{vkt}$. The conclusion that one can draw is that when infrastructure is priced at its average cost (as it is), users drive more than if infrastructure utilization were priced at marginal costs; while when vehicle use is priced at the marginal cost (as it is) users drive more than if it were priced at its average cost. Efforts to change travel behavior through more efficient price signals should consider these facts.

The single largest cost category is freeflow travel time, and as the economy grows (and values of time become higher) time can expect to remain the most costly input to highway travel barring major increases in travel speed. Congestion is not as important in intercity travel, though for urban travel it may very well be. Accidents are the largest external cost on an average cost basis, though to what extent they are external is the subject of debate.

The uncertainties around the cost of air pollution and global warming are clearly large, but even a ten-fold increase in estimate of these costs amounts to only a $13 \%$ increase in the total cost of auto travel (and a somewhat higher percent of the internal costs of auto travel). Internalizing pollution costs should not be expected to have a great effect on intercity auto demand given the low price elasticity that has been found historically.

Table 11. Summary of variables

\begin{tabular}{|c|c|c|}
\hline Section & Variable & Definition \\
\hline 3. General & $C_{T}, C_{A}, C_{N}, C_{E}, C_{I}$ & Costs: time, accident and safety, noise, environment, infrastructure \\
\hline 3. General & $C_{U T}, C_{U N}$ & User costs (total, net) $(\$ / \mathrm{yr})$ \\
\hline 3. General & $F C$ & Full cost \\
\hline 3. General & $T_{U}$ & User transfer costs $(\$ / y r)$ \\
\hline 4. User & $A$ & Age of automobile $=1996$, model year \\
\hline 4. User & $A C_{U N}, M C_{U N}$ & Average, marginal net user costs \\
\hline 4. User & $C_{c}$ & Cost of collision (insured) $(\$ / \mathrm{yr})$ \\
\hline 4. User & $C_{d}(A, Y)$ & Cost of depreciation ( $\$ / \mathrm{yr})$ as function of years and output \\
\hline 4. User & $C_{f}$ & Cost of fire and theft (insured) $(\$ / y r)$ \\
\hline 4. User & $C_{g}, C_{o}, C_{t}$, & Cost of gas, oil, tires $(\$ / \mathrm{km})$ \\
\hline 4. User & $C_{l}$ & Cost of licenses, fees, and taxes $(\$ / y r)$ \\
\hline 4. User & $C_{p}$ & Cost of property damage and liability (insured) $(\$ / y r)$ \\
\hline 4. User & $M$ & Make 1 if the car was a Ford Taurus, 0 if it was a Honda Accord \\
\hline 4. User & $P$ & asking price of used car (current \$). \\
\hline 4. User & $\beta x$ & coefficients from price model \\
\hline 4. User & $Y$ & Output in distance traveled per year $(\mathrm{km})$ \\
\hline 5. Infrastructure & $C_{k}, C_{m}, C_{l}$ & $\begin{array}{l}\text { annualized capital cost, annual expenditures on maintenance, annual } \\
\text { expenditures operations and administration }\end{array}$ \\
\hline 5. Infrastructure & ESAL & Equivalent standard axle loading \\
\hline 5. Infrastructure & ICIn & Incremental cost of infrastructure of $n$th vehicle \\
\hline 5. Infrastructure & $M C I$ & Marginal cost of infrastructure by vehicle class $i$ \\
\hline 5. Infrastructure & $N_{l}, N_{w}$ & Network length, network width \\
\hline 5. Infrastructure & $P_{k}, P_{l}, P_{m}$ & Price of capital, labor, materials \\
\hline 5. Infrastructure & $S$ & Scale economies \\
\hline 5. Infrastructure & $T E(Y) T E_{L R}, T E_{S R}$ & $\begin{array}{l}\text { total expenditures (infrastructure) (as a function of output, long run, } \\
\text { short run) }\end{array}$ \\
\hline 5. Infrastructure & $Y, Y_{i}, Y_{a}, Y_{s}, Y_{c}$ & $\begin{array}{l}\text { output (million VMT/year) general, by mode, auto, single truck, } \\
\text { combination truck }\end{array}$ \\
\hline 6. Time & $L$ & Link segment length $(\mathrm{km})$ \\
\hline 6. Time & $T C_{T} M C_{T} A C_{T}$ & Total, marginal, average cost time (min) \\
\hline 6. Time & $V_{f}$ & Freeflow speed $(\mathrm{km} / \mathrm{min})$ \\
\hline 6. Time & $V_{T}$ & Value of time \\
\hline 6. Time, 8. Noise & $Q_{h}, Q_{h o}$ & Flow per hour, capacity per hour \\
\hline 7. Accident and safety & $V_{L}$ & Value of life \\
\hline 8. Noise & $f_{D}, f_{H}, f_{C}$ & noise model adjustments (density, house value, cost per dB(A)) \\
\hline 8. Noise & $H_{\mathrm{s}}$ & Housing units per strip \\
\hline 8. Noise & $i$ & interest rate \\
\hline 8. Noise & $n$ & number of years in noise model \\
\hline 8. Noise & NDI & Noise depreciation index \\
\hline 8. Noise & $N E F, N E F_{a}, N E F_{b}$ & Noise exposure forecast, before, after \\
\hline 8. Noise & $s$ & $10 \mathrm{~m}$ by $1 \mathrm{~km}$ strips in noise models \\
\hline 8. Noise & $T C_{N} M C_{N} A C_{N}$ & Total, marginal, average cost noise $(\$)$ \\
\hline 8. Noise & $V_{H}$ & Value of house \\
\hline
\end{tabular}


Use of the point estimates of marginal or average cost should be treated cautiously, the more important contribution is the development of cost functions which can be applied to specific circumstances and provide information about the economic structure of specific cost items of intercity highway transportation.

Acknowledgements - The authors gratefully acknowledge the contribution of Adib Kanafani, a co-author of the larger report from which much of this paper is drawn. The authors also thank three anonymous reviewers for their helpful comments. This research was funded by the California High Speed Rail Commission and California Department of Transportation as part of a study on The Full Cost of Intercity Transportation: An Intermodal Comparison (UCB-ITSRR-96-3). The results and opinions presented herein reflect the work of the authors, and not the funders.

\section{REFERENCES}

AAA (American Automobile Association) (1993) Your Driving Costs. Runzheimer International, Rochester, WI.

Boske, L. B. (1988) Alternative formulations of the Federal Highway Administration's bid price index for highway construction. Logistics and Transportation Review 24(2), 165-174.

Bureau of Census (1993) The Statistical Abstract of the United States. Bureau of Census, Washington DC.

Bureau of Labor Statistics (1995) State and industry average annual pay of 1993 and 1994. Press Release of Government Salaries, 19 September. BLS, Washington, DC.

California Air Resources Board (1991) Methodology to Calculate Emission Factors for On-Road Motor Vehicles. CARB, Sacramento, CA.

Delucchi, M. A. (1996) The Annualized Social Cost of Motor-Vehicle Use in the United States, based on 1990-1991 Data. (UCD-ITS-RR-96-3) Institute of Transportation Studies, University of California at Davis, Davis CA.

Federal Aviation Administration (1989) Economic Value for Evaluation of FAA Investment and Regulatory Programs. FAA, Washington, DC.

FHWA (Federal Highway Administration) (1982) Final Report on the Federal Highway Cost Allocation Study: Report of the Secretary of Transportation to the United States Congress. FHWA, Washington DC.

FHWA (Federal Highway Administration) (1993) Highway Statistics 1992. FHWA Office of Highway Information Management, Washington DC.

FHWA (Federal Highway Administration) (1994) Price Trends for Federal Aid Highway Construction, Fourth Quarter 1993, p. 7. FHWA, Washington, DC.

Fuller, J., Hokanson, B., Haugard, J. and Stoner, J. (1983) Measurements of Highway User Interference Costs and Air Pollution and Noise Damage Costs. Institute of Urban and Regional Research, University of Iowa, Ames, IA.

Gillen, D. W., Hansen, M., Mehndiratta, S. R. and Soderberg, T. (1994). The Impact of Air Transportation Technology on Aggregate and Sectoral Economic Efficiency and Growth in California. (UCB-ITS-RR-94-18) Institute of Transportation Studies, University of California at Berkeley, Berkeley, CA.

Hensher, D. A. (1995) Value of travel time savings in personal and commercial automobile travel. In Proceedings of Conference on Social Cost-Benefit Analysis, 6-8 July 1995. U.S. Bureau of Transportation Statistics, Irvine, CA.

IBI Group (1995) Full cost transportation pricing study: final report to transportation and climate change collaborative.

INRETS (1993) Impact des Transport Terrestres sur L'Environment: Methodes d'evaluation et couts sociaux. Synthese Inrets No. 23, Inrets, Paris.

IWW/INFRAS, (1995) External Effects of Transport, for International Union of Railways. IWW-Karlsruhe University and INFRAS Consultants, Karlsruhe, Germany.

Keeler, T. E., Small, K. and Associates (1975) The Full Costs of Urban Transport, Part III: Automobile Costs and Final Intermodal Cost Comparisons (Monograph 212). Institute of Urban and Regional Development, University of California at Berkeley, Berkeley, CA.

Levinson, D., Gillen, D. Kanafani, A. and Mathieu, J. (1996) The Full Cost of Intercity Transportation: An Intermodal Comparison. (UCB-ITS-RR-96-3) Institute of Transportation Studies, University of California at Berkeley, Berkeley CA.

Levinson, D., Gillen, D. and Kanafani, A. (1998) The social costs of intercity passenger transportation: a review and comparison of air and highway. (TRB980274) Presented at Transportation Research Board 77th Annual Meeting, Washington, DC, 11-15 January, Transport Reviews, in press.

Mackenzie, J., Dower, R. C. and Chen, D. (1992) The Going Rate: What it Really Costs to Drive. World Resources Institute, Washington, DC.

Miller, P. and Moffet, J. (1993) The Price of Mobility: Uncovering the Hidden Costs of Transportation. Natural Resources Defense Council, San Francisco, CA.

Miller, T. (1992) The Costs of Highway Crashes. FHWA, Washington, DC.

Modra, J. D. and Bennett, D. W. Cost-benefit analysis of the application of traffic noise insulation measures to existing houses. In Forum Papers of 10th Australian Research Forum, Vol. 1, Melbourne, 13-15 May 1985, pp. 63-86.

Mohring, H. D. and Harwitz, I. (1962) Highway Benefits: An Analytical Framework. Northwestern University Press, Evanston, IL.

Nelson, J. P. (1982) Highway noise and property values: a survey of recent evidence. Journal of Transport Economics and Policy, May, 128.

Nordhaus, W. (1994) Managing the Global Commons. MIT Press, Cambridge MA.

Quinet, E. (1990) The Social Cost of Land Transport (OECD Environment Monograph 32). OECD, Paris.

Small, K. A. and Kazimi, C. (1995) On the costs of air pollution from motor vehicles. Journal of Transport Economics and Policy, January, 7-32.

Small, K., Winston, C. and Evans, C. (1989) Road Work: A New Highway Pricing and Investment Policy. Brookings Institute, Washington, DC.

Spulber, D. (1989) Regulation and Markets. The MIT Press, Cambridge, MA. 
Sullivan, E. C. and Hsu, C. (1988) Accident Rates along Congested Freeways. (UCB-ITS-RR-88-6) Institute of Transportation Studies, University of California at Berkeley, Berkeley, CA.

Transportation Research Board (1985) Highway Capacity Manual, Special Report 209. TRB, Washington, DC.

Winston, C. (1991) Efficient transportation infrastructure policy. Journal of Economic Perspectives 5(1), 113-127. 